Revue d'histoire de l'Amérique française

REVUE D.HISTOIRE DE L'AMÉRIQUE FRANÇAISE

LACROIX, Benoît, o.p., L'historien au Moyen Age.

Montréal/Paris, 1971. 301 p. « Conférences Albert-le-Grand

1966 »。

\title{
Joseph-Claude Poulin
}

Volume 25, numéro 3, décembre 1971

URI : https://id.erudit.org/iderudit/303110ar

DOI : https://doi.org/10.7202/303110ar

Aller au sommaire du numéro

Éditeur(s)

Institut d'histoire de l'Amérique française

\section{ISSN}

0035-2357 (imprimé)

1492-1383 (numérique)

Découvrir la revue

Citer ce compte rendu

Poulin, J.-C. (1971). Compte rendu de [LACROIX, Benoît, o.p., L'historien au

Moyen Age. Montréal/Paris, 1971. 301 p. "Conférences Albert-le-Grand 1966 ».]

Revue d'histoire de l'Amérique française, 25(3), 421-422.

https://doi.org/10.7202/303110ar d'utilisation que vous pouvez consulter en ligne.

https://apropos.erudit.org/fr/usagers/politique-dutilisation/ 
LACRoIx, Benoît, o.p., L'historien au Moyen Age. Montréal/Paris, 1971. 301 p. "Conférences Albert-le-Grand 1966".

L'ouvrage est divisé en trois parties d'inégale longueur. Le premier chapitre, qui compte pour presque la moitié de l'œuvre, analyse en détail l'attitude de l'historien médiéval envers ses sources et scrute ses méthodes de travail. Le second examine plus brièvement ses intentions et ses motivations. Enfin, le troisième situe le genre historique dans la culture médiévale et l'historien par rapport à son public.

La caractéristique principale de cet ouvrage est de s'appuyer sur une quantité énorme de textes, très généreusement traduits; l'inconvénient qui en résulte à la lecture est un écrasement de l'argumentation par la documentation et l'apparat critique. Par contre, cette démarche quelque peu morcelée a l'avantage de nous mettre en contact direct avec l'histoire en train de se faire, de rendre un écho immédiat des doutes et des enthousiasmes de l'historien au travail.

La principale réserve que nous ayons sur ce procédé d'exposition est son caractère linéaire. La démarche adoptée à la fin du troisième chapitre et dans la conclusion, où est explicitement posé le problème du passage de l'historiographie médiévale à l'historiographie moderne, aurait mérité, à notre avis, d'être étendue à l'ensemble de l'œuvre: l'historien 
du Moyen Age a-t-il conçu et conduit son travail de façon identique d'un bout à l'autre du millénaire médiéval ... ? Même si c'est "sans théories avouées", la perception du temps, l'horizon géographique ou l'esprit critique sont-ils restés immuables du Ve au XVe siècle ? De ce point de vue, les conférences de l'A. ont souligné davantage les permanences que les changements, sans doute à bon droit.

Quelques taquineries de forme, comme il se doit: de leur état premier de conférences, ces chapitres maintenant rédigés dans une langue agréable ont gardé quelques traces un peu familières de la langue parlée (p. 104, 195). Les traductions du latin sont à la fois élégantes et assez proches du texte, malgré quelques incartades comme le "tout de go" (p. 27, 177, 260). Déplorons enfin deux anglicismes: item (p. 90) et surtout décade mis pour décennie (p. 89, 270).

En plus de trouver une solide initiation au genre historiographique du Moyen Age, le médiéviste profitera de la grande familiarité de l'auteur avec les textes et leur maniement; à cette valeur exemplaire s'ajoute une riche moisson de propositions pour la poursuite de recherches en historiographie ou dans des domaines connexes; nous avons dénombré une bonne quinzaine de ces suggestions, sans compter l'énumération finale de la conclusion (p. 275s.).

Mais l'A. n'a pas travaillé exclusivement à l'intention des médiévistes. A travers son œuvre, c'est à tous les historiens qu'il s'adresse; l'objectif visé nous semble être une démonstration de la dignité de l'histoire et du métier d'historien: "métier exigeant et délicat", hier comme aujourd'hui.

Département d'histoire

Joseph-Claude Poulin Université Laval 